\title{
Tuning Shape of Barium Titanate Nanocubes by Combination of Oleic Acid/tert-Butylamine Through Hydrothermal Process
}

Qiang Ma*, Ken-ichi Mimura, Kazumi Kato

National Institute of Advanced Industrial Science and Technology (AIST),

2266-98 Anagahora, Shimoshidami, Moriyama, Nagoya, 463-8560, Japan.

E-mail: qiang-ma@aist.go.jp

(C) 2015. This manuscript version is made available under the Elsevier user license 
The shape and surface morphology of mono-dispersed barium titanate $\left(\mathrm{BaTiO}_{3}\right)$ nanocrystals were controlled by tuning the composition of hydrothermal reaction system. High quality $\mathrm{BaTiO}_{3}$ nanocubes with the smooth surface and 90 degree standard corner angle were synthesized by the hydrothermal method using a relatively low concentration of oleic acid and tert-butylamine, which were used as surfactant and additive, respectively. The average size of $\mathrm{BaTiO}_{3}$ nanocubes was $\sim 25 \mathrm{~nm}$ and the size distribution was relatively narrow. As a large amount of surfactant and additive was employed, $\mathrm{BaTiO}_{3}$ nanocrystals with convex structure were synthesized. The terrace structure were developed at the $\{100\}$ surface of the nanocrystals. Here, we analyzed systematically the role of oleic acid and tert-butylamine on the surface morphology of $\mathrm{BaTiO}_{3}$ nanocrystals. Our study demonstrates the possibility of synthesizing high quality $\mathrm{BaTiO}_{3}$ nanocubes for commercial application. These findings can be applied on other perovoskite nanomaterials.

Keyword: Barium titanate, Nanocubes, Hydrothermal crystal growth, Shape controlling, Oleic acid, t-Butylamine. 


\section{Introduction:}

As one of important perovskite ferroelectric oxides, barium titanate $\left(\mathrm{BaTiO}_{3}\right)$ is widely used in microwave devices and modern microelectronics such as multilayer ceramic capacitors (MLCC), random access memories, radar, communication systems, pressure transducers, etc [1-8]. $\mathrm{BaTiO}_{3}$ nanomaterials have been fabricated by many routines, such as solid-state calcination, sol-gel technique, hydrothermal treatment, and polymeric precursor method [9-12]. Among these methods, hydrothermal treatment is an environmentally friendly method, easily synthesizing mono-dispersed nanopowders $[13,15]$. Moreover, the control of the particle size and the morphology can be realized by modifying the parameters of hydrothermal synthesis, such as the raw material ratios, reaction time, temperature, and surfactants, etc $[16,18]$. Compared with other kinds of morphology, the cubic shape of $\mathrm{BaTiO}_{3}$ nanomaterials is of interest because of its peculiar symmetries and the specific superstructures. $\mathrm{BaTiO}_{3}$ nanocubes can produce a close-packed structure and impulse the development of "bottom-up" process, which is important for the next generation devices. $\mathrm{BaTiO}_{3}$ nanocubes possess unique physical and chemical properties that are strongly related with their size, shape, and surface chemistry [19]. It has been reported $\mathrm{BaTiO}_{3}$ nanocubes with several tens nm edge length maintained dielectric property. Therefore, the synthesis of $\mathrm{BaTiO}_{3}$ nanocubes with well-controlled shape and surface morphology is fundamentally and technologically 
interest to pave the way to the miniaturization of the dielectric device.

Our group has successfully synthesized $\mathrm{BaTiO}_{3}$ nanocubes with $15 \mathrm{~nm}$ in size by hydrothermal method using Ti-based hydrous gel with surfactant and additives and has also found after sintering highly ordered $\mathrm{BaTiO}_{3}$ nanocube-assembled films possess a high dielectric constant of approximately 3000 with relatively low loss tangent [18, 20-21]. Recently, the size of $\mathrm{BaTiO}_{3}$ nanocubes were controlled by tuning barium and titanium precursor concentration. The average size of nanocubes varied from $\sim 15 \mathrm{~nm}$ to $\sim 30 \mathrm{~nm}$ [22]. However, when the size of nanocubes increased, the surface of $\mathrm{BaTiO}_{3}$ nanocubes became rough and their corner angles deviated from $90^{\circ}$. The kind of irregular morphology of nanocubes not only influences the study of "size effect", but also hinders their applications on the "bottom-up" assembling process. Self-assembly of nanocubes into tailored structures is a promising strategy for production and design of materials with new functions. So, to synthesize size-controlled $\mathrm{BaTiO}_{3}$ nanocubes with neat surface morphology and standard corner angle is important for both their theoretical investigation and technological applications.

In this work, the main research target is to study an effective way to synthesize high-quality larger-sized $\mathrm{BaTiO}_{3}$ nanocubes with standard cubic structure. We explored the effects of reaction conditions such as molar ratio of surfactant and additive, reaction 
time, and the concentration of hydroxide ions on the structure and surface morphology

of $\mathrm{BaTiO}_{3}$ nanocubes. We found that the molar ratio of precursor solution played a critical role in determining the shape of $\mathrm{BaTiO}_{3}$ nanocubes. Size-controlled nanocubes with standard cubic structure and smooth surface morphology were synthesized by tuning the molar ratios of oleic acid and tert-butylamine. In addition, $\mathrm{BaTiO}_{3}$ nanocrystals with convex structure could be produced, and the step structure were developed at the $\{100\}$ surface of the nanocrystals.

\section{Experimental}

In our case, the bis(ammonium lactate) titanium dihydroxide (TALH) was used as the Ti source, which could resolve into water. In a typical synthesis process, $\mathrm{Ba}(\mathrm{OH})_{2}$ and TALH was added into $45 \mathrm{~mL}$ of distilled water in a $100 \mathrm{~mL}$ autoclave. The Ba/Ti ratios were 1: $1 . \mathrm{NaOH}$ aqueous solution $(5 \mathrm{M})$ was added into the aqueous solution under mechanical stirring to tune the $\mathrm{pH}$ value. Then, the tert-butylamine and oleic acid were added into the solution. The sealed autoclave was heated at $220^{\circ} \mathrm{C}$ for $72 \mathrm{~h}$ under mechanical stirring, and then cooled at room temperature. After the synthesis, the precipitate was centrifugally separated and washed twice by absolute ethanol. After drying, the precipitate was dispersed into toluene. The $\mathrm{BaTiO}_{3}$ nanocubes were characterized by X-ray diffractometry (XRD, Rigaku RINT-2100V). The morphology 
of the prepared $\mathrm{BaTiO}_{3}$ nanocubes was investigated by using a field emission scanning electron microscope (FESEM, JEOL JSM-6335FM) and a transmission electron microscopy (TEM; Model JEM-2010F, with an accelerating voltage of $200 \mathrm{kV}$ ).

\section{Results and Discussion:}

Figure 1 shows FE-SEM image, TEM image, high-resolution TEM (HR-TEM) image and XRD result of $\mathrm{BaTiO}_{3}$ nanocubes with an average size of $\sim 30 \mathrm{~nm}$, which were synthesized by the hydrothermal process. Several diffraction peaks were showed in the XRD pattern of $\mathrm{BaTiO}_{3}$ nanocubes (Figure 1 (d)) [17, 23-24]. No peaks of any other phases or impurities were detected. The XRD result and HRTEM image provided evidence that the $\mathrm{BaTiO}_{3}$ nanocubes belonged to the perovskite structure. As shown in the HR-TEM images of Figure 1 (c), the surface of nanocubes was rough. As well known, the amount of surfactant and additives can modify the shape of nanocrystals [16, 18-19]. To investigate the synthesis of nanocubes with standard cubic structure and neat surface morphology, the molar ratios of oleic acid and tert-butylamine were tuned step by step in our case. The synthesis recipe of $15 \mathrm{~nm} \mathrm{BaTiO}_{3}$ nanocubes was used as reference to estimate the preliminary values of these parameters $[18,21]$.

During the crystal growth process, oleic acid adsorbed on the surface of nanocrystals through coordination with barium metal ion. Thus, as for oleic acid, the total surface 
area of $\mathrm{BaTiO}_{3}$ nanocubes with an average size of $\sim 30 \mathrm{~nm}$ was utilized to estimate the molar ratio of oleic acid in this work. Ideally, the ratio of total surface area of $30 \mathrm{~nm}$ nanocubes to $15 \mathrm{~nm}$ nanocubes was calculated by the follow equation:

$$
\frac{S_{30 \mathrm{~nm}}}{S_{15 \mathrm{~nm}}}=\frac{N_{30 \mathrm{~nm}} * 30^{2} * 6}{N_{15 \mathrm{~nm}} * 15^{2} * 6}
$$

where $S_{30 \mathrm{~nm}}$ and $S_{15 \mathrm{~nm}}$ were the surface area of $30 \mathrm{~nm}$ nanocubes and $15 \mathrm{~nm}$ nanocubes, respectively. $\mathrm{N}_{30 \mathrm{~nm}}$ and $\mathrm{N}_{15 \mathrm{~nm}}$ were the total number of $30 \mathrm{~nm}$ nanocubes and $15 \mathrm{~nm}$ nanocubes, respectively. If all of starting materials reacted into $\mathrm{BaTiO}_{3}$ nanocubes, $\mathrm{N}_{30 \mathrm{~nm}}$ and $\mathrm{N}_{15 \mathrm{~nm}}$ could be calculated by the follow equation:

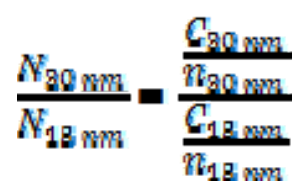

where $\mathrm{C}_{30 \mathrm{~nm}}$ and $\mathrm{C}_{15 \mathrm{~nm}}$ were the concentration of starting materials for synthesizing $30 \mathrm{~nm}$ nanocubes and $15 \mathrm{~nm}$ nanocubes, respectively. The $n_{30 \mathrm{~nm}}$ and $n_{15 \mathrm{~nm}}$ were the number of barium ion in single nanocube. Under ideal condition, $n_{30 \mathrm{~nm}}$ and $n_{15 \mathrm{~nm}}$ were proportional with the volume of single $\mathrm{BaTiO}_{3}$ nanocube, which were denoted as $\mathrm{V}_{30 \mathrm{~nm}}$ and $\mathrm{V}_{15 \mathrm{~nm}}$.

$$
\frac{n_{\mathrm{g} 9 \mathrm{~mm}}}{n_{1 \mathrm{~mm}}}=\frac{b_{20 \mathrm{~mm}}}{E_{18 \mathrm{~mm}}}
$$

In this case, the concentrations of $\mathrm{Ba}(\mathrm{OH})_{2}$ and TALH were half of those of $15 \mathrm{~nm}$ nanocubes recipe. Combining with the concentration of starting materials, it was 
calculated that the total surface area of $30 \mathrm{~nm} \mathrm{BaTiO}{ }_{3}$ nanocubes was about the fourth part of that of $15 \mathrm{~nm}$ nanocubes. Based on the recipe of $15 \mathrm{~nm} \mathrm{BaTiO}_{3}$ nanocubes (The molar ratio of barium to oleic acid is 1 : 12.), the ideal molar ratios of $\mathrm{Ba} /$ oleic acid for $30 \mathrm{~nm} \mathrm{BaTiO}$ nanocubes is calculated as 1: 3 .

The previous articles reported that one of the roles of tert-butylamine was to connect with the hydroxyl group of Ti octahedral and stabilize them $[18,21]$. So, as for tert-butylamine, the concentration of TALH was utilized to estimate its molar ratio for synthesizing larger-sized $\mathrm{BaTiO}_{3}$ nanocubes. The preliminary values of the molar ratio of tert-butylamine in this work were set to half of that of $15 \mathrm{~nm}$ nanocubes recipe (The molar ratio of barium to oleic acid is 1: 12.). According on above calculation, the preliminary value of the molar ratios of Ba: tert-butylamine: oleic acid was 1:6:3.

Figure 2 showed the morphology of $\mathrm{BaTiO}_{3}$ nanocubes, which were synthesized by using the hydrothermal method at $220^{\circ} \mathrm{C}$ under different molar ratios of reaction environment. Basing on the TEM images, it can be inferred that the shape and surface morphology of the synthesized $\mathrm{BaTiO}_{3}$ nanocubes has been affected by the molar ratios of aqueous system $\left(\mathrm{Ba}(\mathrm{OH})_{2}\right.$ : tert-butylamine: oleic acid). As the molar ratio varied from 1: 6: 3 to 1: 6: 8 , the surface morphology of $\mathrm{BaTiO}_{3}$ nanocubes became smooth and their shapes showed standard cubic structure. When the molar ratios reached 1: 6: 
10 times, wavy surface and damaged corners appeared in most of $\mathrm{BaTiO}_{3}$ cubic structures. When the molar ratio was 1: 6: 12, the similar results were obtained and almost all of $\mathrm{BaTiO}_{3}$ nanocrystals showed quasi-cubic structure. Once the molar ratio of oleic acid was increased into 18 times of that of $\mathrm{Ba}(\mathrm{OH})_{2}, \mathrm{BaTiO}_{3}$ nanocrystals with convex structure were produced. The results indicated the amount of oleic acid played an important role on the shape and surface morphology of $\mathrm{BaTiO}_{3}$ nanocubes.

In the present synthesis procedure, oleic acid ensured the stability of the colloidal solutions through electrostatic (via the $\mathrm{COO}^{-}$groups) and steric repulsions. Oleic acid could act as capping agent to coordinate the surface of $\mathrm{BaTiO}_{3}$ nanocubes $[18,22-25]$, where the $\mathrm{COO}^{-}$group is bonded to barium ions $\left(\mathrm{Ba}^{2+}\right)$. The adsorption is considered to occur at the surface of tiny crystalline $\mathrm{BaTiO}_{3}$ nuclei at the beginning stage of the hydrothermal reaction. As well known, the shapes and surface morphology of final $\mathrm{BaTiO}_{3}$ cubic crystals were determined by the ratio of the growth rate along the $<100>$ directions to another crystal directions. The preferentially selective adsorption of oleic acid on $\{100\}$ crystal surfaces could play a crucial role in the shape control of nanocubes [22, 26-28]. When the amount of oleic acid varied from 3 times to 8 times of that of $\mathrm{Ba}(\mathrm{OH})_{2}$, it first interacted with the $\{100\}$ planes of $\mathrm{BaTiO}_{3}$ nanocrystal and the preferential adsorption on the $\{100\}$ faces confined crystal growth along the directions. 
Thus, the cubic-like $\mathrm{BaTiO}_{3}$ nanocrystals were synthesized, as shown in Figure 2 (b) and (c). Due to the low concentration of oleic acid (Figure 2 (a)), some aggregation phenomenon existed in the final products. When the concentration of oleic acid was increased step-by-step and reached to an optimal value, the ratio of the growth rate of $\mathrm{BaTiO}_{3}$ nanocrystals along the $<100>$ directions to another crystal directions decreased gradually and the $\{100\}$ faces were protected well in final products. So, the nanocubes showed the standard cubic structure and neat surface morphology, as shown in Figure 2 (c). When the molar ratios of oleic acid continued to be increased, the oleic acid presented dominantly in the form of a dimer rather than in carboxylate anions because of the hydrogen-bonding interaction [29-30]. The absence of carboxylate anions leaded to a weaker interaction between the surfactant and the surfaces of nanocrystal. This phenomenon influenced the role of oleic acid and resulted in the formation of larger-sized nanoparticles with convex morphology. In addition, based on previous reports, when a large excess of oleic acid was employed, the adsorption of oleic acid on $\{100\}$ faces was saturated and another faces were also capped by oleic acid [31]. This situation could inhibit the growth in the capped direction and influence the final shape of nanocrystals. Thus, it is considered that the transformation on the morphology of $\mathrm{BaTiO}_{3}$ nanocubes in Figure 2 is attributed to the molar ratios of oleic acid in reaction 
system.

Figure 3 showed the HRTEM images of $\mathrm{BaTiO}_{3}$ nanocubes, synthesized by using corresponding molar ratios of Figure 2. All of high resolution TEM images revealed that the nanocubes were single-crystalline. Four (100) and (110) planes in all of $\mathrm{BaTiO}_{3}$ nanocubes were identified from the fast fourier transform (FFT) profiles of the HRTEM image. The FFT patterns further indicate the high phase purity and crystallinity of as-synthesized $\mathrm{BaTiO}_{3}$ nanocubes. Careful examination of Figures 3 (b) and (c) elucidated that the nanocrystals were cubic and have sharply faceted edges. The lattice fringes were parallel with or made an angle of $90^{\circ}$ with the edge of the nanocubes and went across the nanocubes without any distortion. As shown in Figures 3 (d) and (e), the sharp edges and smooth surface of $\mathrm{BaTiO}_{3}$ nanocubes disappeared. Especially, it can be observed from Figure 3 (f) that the step and terrace structure were developed at the $\{100\}$ surface of the nanocrystals with convex structure. The distances of the lattice fringes on surface area of Figure 3 (f) were $0.398 \mathrm{~nm}$ and $0.282 \mathrm{~nm}$, which were close to the $\{100\}$ and $\{110\}$ lattice spacing of cubic phase of $\mathrm{BaTiO}_{3}$, respectively. It was considered that the co-existence of different crystal planes on the surface area resulted in the formation of $\mathrm{BaTiO}_{3}$ nanocrystals with convex shape.

Tert-butyalmine has been widely used as reducing agents to produce novel metal 
nanoparticles [32-33]. Meantime, tert-butyalmine is also an effective additive for synthesizing metal oxide nanomaterials $[18,31]$. Figure 4 showed the TEM images of $\mathrm{BaTiO}_{3}$ nanocubes, which were produced by using hydrothermal method at $220^{\circ} \mathrm{C}$ with different molar ratios of tert-butylamine /oleic acid. When the molar ratio varied from 1: 3 to 1: 1 (tert-butylamine: oleic acid), the shape of $\mathrm{BaTiO}_{3}$ nanocrystals changed from convex structure to cubic structure (Figure 4 (a) and (b)). However, comparing the TEM and high-resolution images in Figure 4 (b) and (c), the surface of $\mathrm{BaTiO}_{3}$ nanocubes became rough as the molar ratio changed from 1:1 to $4: 3$. The results indicated that a suitable tert-butylamine /oleic acid combination was critical for the highly cubic-shape structure. In our synthesis procedure, tert-butylamine showed one triple-positive-role at least on the formation of nanocubes. Firstly, the molecular of tert-butylamine can stabilize the hydroxyl group of Ti octahedral, and secondly, the strong polarity of tert-butylamine is critical for the formation of $\mathrm{BaTiO}_{3}$ phase $[18,21-22]$. Thirdly, tert-butylamine can enhance the deprotonation of oleic acid, as mentioned above. It has been reported that the amine can promote the deprotonation of OLA [26]. Tert-butylamine will react with oleic acid with the follow process:

$$
\mathrm{C}_{17} \mathrm{H}_{33} \mathrm{COOH}+\left(\mathrm{CH}_{3}\right)_{3} \mathrm{CNH}_{2} \rightarrow \mathrm{C}_{17} \mathrm{H}_{33} \mathrm{COO}^{-}+\left(\mathrm{CH}_{3}\right)_{3} \mathrm{CNH}_{3}^{+}
$$

The deprotonated process of oleic acid molecular can improve the connection between 
oleic acid and barium ions, which is crucial for the shape of $\mathrm{BaTiO}_{3}$ nanocubes. When the molar ratio of tert-butylamine /oleic acid was increased from $1: 3$ to $1: 1$ (Figure 4 (a) and (b)), the strong deprotonation of oleic acid in aqueous solution could be promoted and the formation of the dimer was prevented. The deprotonated oleic acid may cap the $\{100\}$ faces of $\mathrm{BaTiO}_{3}$ nanocrystals and enhance the growth probability of cubic structures. However, if a huge amount of tert-butylamine existed in the synthesis system, as shown in Figure 4 (c), the excess tert-butylamine molecular were also connected the crystal faces and influence the growth speed along these directions [31-32]. So, the roughness of surface morphology of $\mathrm{BaTiO}_{3}$ nanocubes was attributed to the huge concentration of tert-butylamine in aqueous system.

The reaction time of hydrothermal synthesis process showed obvious influence on the morphology of $\mathrm{BaTiO}_{3}$ nanocubes. Figure 5 demonstrated the relationship between the morphology of nanocubes and the reaction time. As the reaction time increased from 48hours to 72 hours (Figure 5 (a) and (b)), the quality of the shape of $\mathrm{BaTiO}_{3}$ nanocubes was improved. However, as the reaction time was 88 hours and 96 hours (Figure 5 (c) and (d)), the surface morphology of nanocubes became rough. This result indicated that over-long hydrothermal time played a negative role on the shape and surface morphology of nanocubes. The connection between the oleic acid and the barium ions 
on the surface of $\mathrm{BaTiO}_{3}$ nanocubes was influenced by the long-time heating treatment. During the long time of hydrothermal treatment, part of the oleic acid was stripped from the surface of $\mathrm{BaTiO}_{3}$ nanocrystals and re-dissolved into the solution. This phenomenon resulted in the change on the growth speeds along $<100>$ crystalline direction of nanocrystals. The surface of $\mathrm{BaTiO}_{3}$ final nanocrystal was not only consisted by six $\{100\}$ faces. So, the morphology of final product was not the cubic-like structure but irregular structure. In our case, the 72-hours hydrothermal treatment was the relative better choice for the formation of $\mathrm{BaTiO}_{3}$ nanocubes.

The alkalinity of the aqueous solution was an important parameter in wet chemical method, which could affect obviously the size and morphology of nanomaterials [34-38]. In our case, the total concentration of hydroxide ions $\left(\mathrm{OH}^{-}\right)$present in the solution (mainly coming from $\mathrm{NaOH}$ ) was responsible for the formation of $\left[\mathrm{Ti}(\mathrm{OH})_{6}\right]^{2-}$ and played an important role on the formation of crystalline $\mathrm{BaTiO}_{3}[18,22,39]$. The FE-SEM images of $\mathrm{BaTiO}_{3}$ nanocrystals synthesized by hydrothermal method with different concentrations of $\mathrm{NaOH}$ were shown in Figure 6. The convex-structured $\mathrm{BaTiO}_{3}$ nanocrystals were synthesized when $0.6 \mathrm{M} \mathrm{NaOH}$ was employed. As the concentration of $\mathrm{NaOH}$ increased 1.0 and $1.2 \mathrm{M}$, the shape of $\mathrm{BaTiO}_{3}$ nanocrystals showed the cubic-like morphology. In contrast, when the concentration of $\mathrm{NaOH}$ was 
$1.5 \mathrm{M}$, the irregular $\mathrm{BaTiO}_{3}$ nanocrystals were produced. The results indicated that the concentration of $\mathrm{NaOH}$ in the solution was crucial for the shape and surface morphology of $\mathrm{BaTiO}_{3}$ nanocrystals.

We showed the arrangement of $\mathrm{BaTiO}_{3}$ nanocubes with different surface morphology (Figure 7). Due to the surface roughness of nanocubes, only the orderly arrangement of $\mathrm{BaTiO}_{3}$ nanocubes could be achieved in several tens micrometers scale by using simple drop-casting method, as demonstrated in Figure 7 (a). However, $\mathrm{BaTiO}_{3}$ nanocubes with convex or terrace structure only showed an irregular arrangement, as shown in Figure 7 (b). The results show the positive role of cubic structures on the self-arrangement of $\mathrm{BaTiO}_{3}$ nanocubes. The orderly arrangement of larger-sized nanocubes indicates the possibility of their application on the study of ferroelectric science and the development of next generation devices. The XRD pattern in the inlet of Figure 7 (a) showed (100) and (200) diffraction peaks with high intensities. Other diffraction peaks, which belong to $\mathrm{BaTiO}_{3}$, showed weak intensities or could not be detected. The peak around $33^{\circ}$ was attributed to the influence of silicon substrate. On the contrary, the XRD pattern in the inlet of Figure 7 (b) demonstrated several diffraction peaks with high intensities, (100), (110), (111), (200), (210) and (211). The results provided the evidence to confirm the orderly arrangement of $\mathrm{BaTiO}_{3}$ nanocubes with standard cubic structure by utilizing a 
simple method of drop-casting instead of very low speed dip-coating method.

\section{Conclusion:}

In this work, the shape and surface morphology of $\mathrm{BaTiO}_{3}$ nanocubes showed a strong relationship with the molar ratio of precursor solution. High quality $25 \mathrm{~nm}$-sized $\mathrm{BaTiO}_{3}$ nanocubes with standard cubic shape and smooth surface morphology were produced by using low molar ratio of $\mathrm{Ba}^{2+}$ : tert-butylamine: oleic acid. As the molar ratio of oleic acid was increased step by step, the shape of $\mathrm{BaTiO}_{3}$ nanocrystals were changed from cubic structure to convex structure and the terrace structure were developed at the $\{100\}$ surface of them. On the other hand, the shape and surface morphology of nanocrystals were sensitive to the increase of the molar ratio of tert-butylamine /oleic acid.

In addition, the roles of the reaction time and the molar concentration of $\mathrm{NaOH}$ on the shape of $\mathrm{BaTiO}_{3}$ nanocrystals were investigated. When the value of the concentration of $\mathrm{NaOH}$ varied from $1.0 \mathrm{M}$ to $1.2 \mathrm{M}$, the cubic-like $\mathrm{BaTiO}_{3}$ nanocrystals could be synthesized successfully. And the 72-hours hydrothermal treatment was a suitable choice for the formation of $25 \mathrm{~nm}$-sized $\mathrm{BaTiO}_{3}$ nanocubes. This work suggests the possibility of synthesizing high quality $\mathrm{BaTiO}_{3}$ nanocubes for their industrial applications. 


\section{ACKNOWLEDGMENTS}

This work was supported by the Advanced Low Carbon Technology Research and

Development Program (ALCA) of Japan Science and Technology Agency (JST).

\section{References}

[1] S. O’Brien, L. Brus, C.B. Murray, J. Am. Chem. Soc. 123 (2001) 12085-12086.

[2] I. I. Naumov, L. Bellaiche, H. Fu, Nature. 432 (2004) 737-740.

[3] R.L. Brutchey, D.E. Morse, Angew. Chem. Int. Ed. 45 (2006) 6564-6566.

[4] D. M. Gill, C. W. Conrad, G. Ford, B. W. Wessels, S. T. Ho, Appl. Phys. Lett. 71 (1997) 1783-1785.

[5] P. S. Tang, D. J. Towner, T. Hamano, A. L. Meier, B. W. Wessels, Opt. Express. 12 (2004) 5962-5967.

[6] L. Wang, Y. He, J. Hu, Q. Qi, T. Zhang, Sens. Actuators, B: Chemical. 153 (2011) 460-464.

[7] F. A. Yildirim, C. Ucurum, R. R. Schliewe, W. Bauhofer, R. M. Meixner, H. Goebel, W. Krautschneider, Appl. Phys. Lett. 90 (2007) 083501-3.

[8] D. Hennings, M. Klee, R. Waser, Adv. Mater. 3 (1991) 334-340.

[9] S. Adireddy, C. K. Lin, B. B. Cao, W. L. Zhou, G. Caruntu, Chem. Mater. 22 (2010) 1946-1948.

[10] S. Moon, H. W. Lee, C. H. Choi, D. K. Kim, J. Am. Ceram. Soc, 7 (2012) 2248-2253.

[11] J. Zhou, Z. C. Yang, CrystEngComm. 15 (2013) 8912-8914.

[12] W. W. Wang, L. X. Cao, W. Liu, G. Su, W. X. Zhang, Ceramics International. 39 (2013) 7127-7134.

[13] U. A. Joshi, S. Yoon, S. Baik, J. S. Lee, J. Phys. Chem. B. 110 (2006) 12249-12256.

[14] S. Moon, H-W. Lee, C-H. Choi, D, K Kim, J. Am. Ceram. Soc. 95 (2012) 2248-2253. 
[15] J. Adam, G. Klein, T. Lehnert, J. Am. Ceram. Soc. 96 (2013) 2987-2993.

[16] C. Hofmann, I. Rusakova, T. O. Ely, D. Prieto-Centurio'n, K. B. Hartman, A. T. Kelly, A. Lüttge, K. H. Whitmire, Adv. Funct. Mater. 18 (2008) 1661-1667.

[17] Y. L Gao, V. V. Shvartsman, A. Elsukova, D. C. Lupascu, J. Mater. Chem. 22 (2012) 17573-17583.

[18] F. Dang, K. Mimura, K. Kato, H. Imai, S. Wada, H. Haneda, M. Kuwabara, Nanoscale. 4 (2012) 1344-1349.

[19] H. Hayashi, T. Noguchi, N. M. Islam, Y. Hakuta, Y. Imai, N. Ueno, Journal of Crystal Growth, 312 (2010) 1968-1972.

[20] K. Mimura, K. Kato, APEX. 7 (2014) 061501-3

[21] K. Kato, K. Mimura, F. Dang, H. Imai, S. Wada, M. Osada H. Haneda, M. Kuwabara, J. Mater. Res. 28 (2013) 2932-2945

[22] Q. Ma, K. Mimura, K. Kato, CrystEngComm. 16 (2014) 8398-8405

[23] L. Ju, T, Sabergharesou, K. G. Stamplecoskie, M. Hegde, T. Wang, N. A. Combe, H.Y. Wu, P. V. Radovanovic, J. Am. Chem. Soc. 134 (2012) 1136-1146

[24] P. K. Dutta, R. Asiaie, S. A. Akbar, W.D. Zhu, Chem. Mater. 6 (1994) 1542-1548

[25] K. Fujinami, K. Katagiri, J. Kamiya, T. Hamanaka, K. Koumoto, Nanoscale. 2 (2010) 2080-2083

[26] T. D. Nguyen, T. O. Do, J. Phys. Chem. C. 113 (2009) 11204-11214.

[27] Y. H. Zheng, Y. M. Tian, H. L. Ma, Y. N. Qu, Z. C. Wang, D. M. An, S. Guan, X. Y. Gao, Colloids Surf. A: Physicochem. Eng. Aspects. 339 (2009) 178-184

[28] Y. Li, J. Liu, Y. Q. Wang, Z. L. Wang, Chem. Mater. 13 (2001) 1008-1014.

[29] W. B Bu, Z.X. Chen, F. Chen, J. L. Shi, J. Phys. Chem. C. 113 (2009) 12176-12185.

[30] Z. H. Zhang, X. H. Zhong, S. H. Liu, D. F. Li, M. Y. Han, Angew. Chem., Int. Ed. 44 (2005) 3466-3470 
[31] C-T. Dinh, T-D. Nguyen, F. Kleitz, T-O. Do, ACS NANO. 3 (2009) 3737-3743.

[32] A. C. Templeton, M. J. Hostetler, C. T. Kraft, R. W. Murray, J. Am. Chem. Soc. 120 (1998) 1906-1911.

[33] Z. K. Wu, M. A. MacDonald, J. Chen, P. Zhang, R. C. Jin, J. Am. Chem. Soc. 133 (2011) 9670-9673.

[34] R. Asiaie, W. D. Zhu, S. A. Akbar, P. K. Dutta, Chem. Mater. 8 (1996) 226-234

[35] B. L. Newalkar, S. Komarneni, H. Katsuki, Materials Research Bulletin. 36 (2001) 2347-2355.

[36] J. J. Urban, L. Ouyang, M-H. Jo, D. S. Wang, H.K. Park, NANO LETTERS. 4 (2004) $1547-1550$.

[37] X. Wang, Y.D. Li, Angew. Chem. Int. Ed. 41 (2002) 4790-4793.

[38] W-C. Huang, L-M. Lyu, Y-C. Yang, M. H. Huang, J. Am. Chem. Soc. 134 (2012) 1261-1267.

[39] N. C. Pramanik, S. I. Seok, B. Y. Ahn, Materials Research Bulletin. 42 (2007) 497-504. 
Figure 1 (a) FE-SEM image, (b) TEM image, (c) high-resolution TEM image and (d) XRD pattern of $\mathrm{BaTiO}_{3}$ nanocubes, which were synthesized by the oleic acid/ tert-butylamine assisted hydrothermal process.

Figure 2 TEM images of $\mathrm{BaTiO}_{3}$ nanocubes, synthesized by using the hydrothermal method at $220^{\circ} \mathrm{C}$ with different molar ratios of $\mathrm{Ba}(\mathrm{OH})_{2}$ : tert-butylamine: oleic acid : (a) $1: 6: 3$; (b) $1: 6: 6$; (c) 1:6: 8; (d) 1:6:10; (e) 1:6:12; (f) 1:6:18.

Figure 3 HRTEM images and FFT patterns of $\mathrm{BaTiO}_{3}$ nanocubes, synthesized by the hydrothermal method with different molar ratios of $\mathrm{Ba}(\mathrm{OH})_{2}$ : tert-butylamine: oleic acid : (a) 1:6:3; (b) 1:6:6; (c) 1:6: 8; (d) 1:6:10; (e) 1:6:12; (f) 1:6:18.

Figure 4 TEM images of $\mathrm{BaTiO}_{3}$ nanocubes, which were produced by using the hydrothermal method at $220^{\circ} \mathrm{C}$ with different molar ratios of tert-butylamine/oleic acid: (a) $1: 3$; (b) $1: 1$; (c) $4: 3$.

Figure 5 TEM images of $\mathrm{BaTiO}_{3}$ nanocubes, which were synthesized by the hydrothermal process at $220^{\circ} \mathrm{C}$ for different reaction time: (a) 48 hours; (b) 72 hours; (c) 88 hours and (d) 96hours.

Figure 6 FE-SEM images of $\mathrm{BaTiO}_{3}$ nanocrystals, which were synthesized by the hydrothermal process at $220^{\circ} \mathrm{C}$ with different concentration of $\mathrm{NaOH}$ : (a) $0.6 \mathrm{M}$; (b) $0.8 \mathrm{M}$; (c) $1.0 \mathrm{M}$; (d) $1.2 \mathrm{M}$ and (e) $1.5 \mathrm{M}$.

Figure 7 (a) The orderly arrangement of $\mathrm{BaTiO}_{3}$ nanocubes (the inset is the corresponding XRD pattern); (b) the random arrangement of $\mathrm{BaTiO}_{3}$ nanocubes with irregular structures (the inset is the corresponding XRD pattern). 


\section{Figure 1}

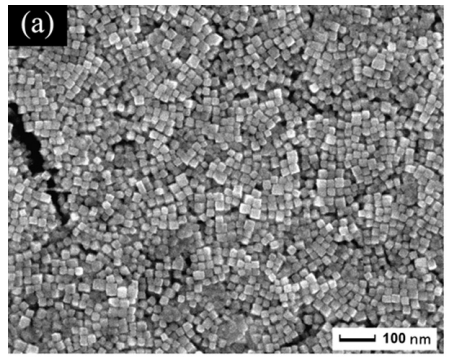

\section{(c)}

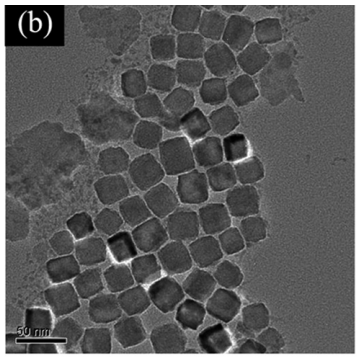

\section{(d)}

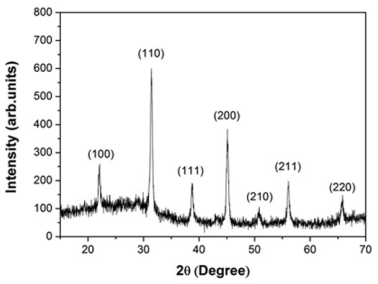




\section{Figure 2}
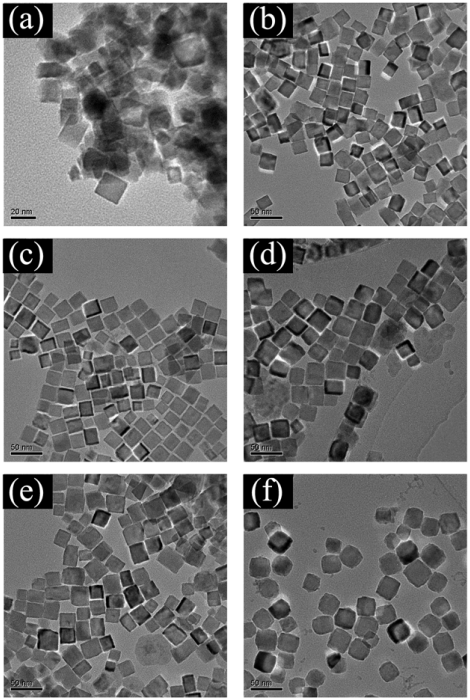


\section{Figure 3}
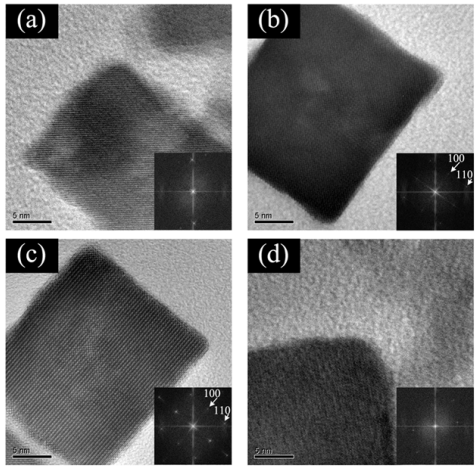

\section{(e)}
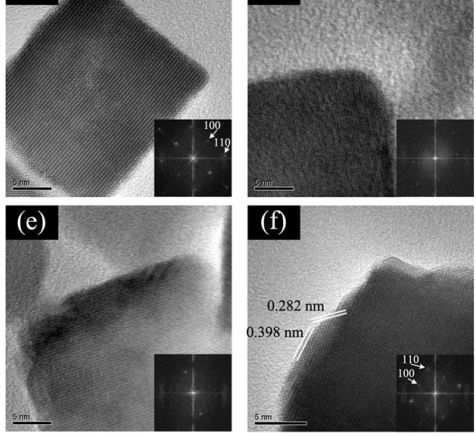
Figure 4
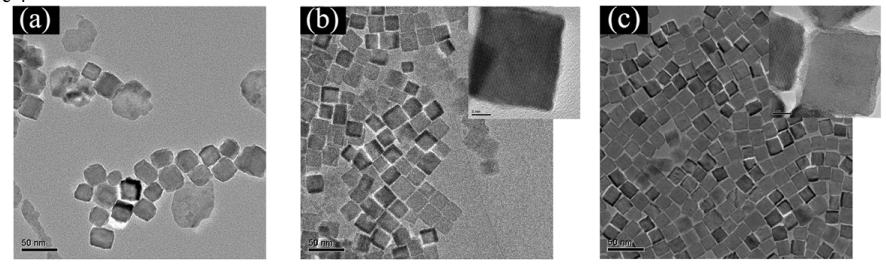
Figure 5
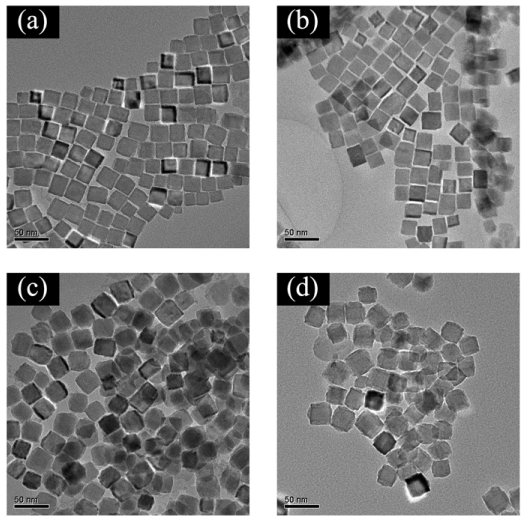


\section{Figure 6}
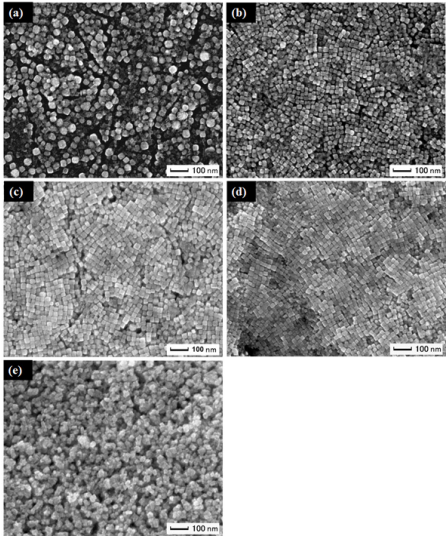


\section{Figure 7}
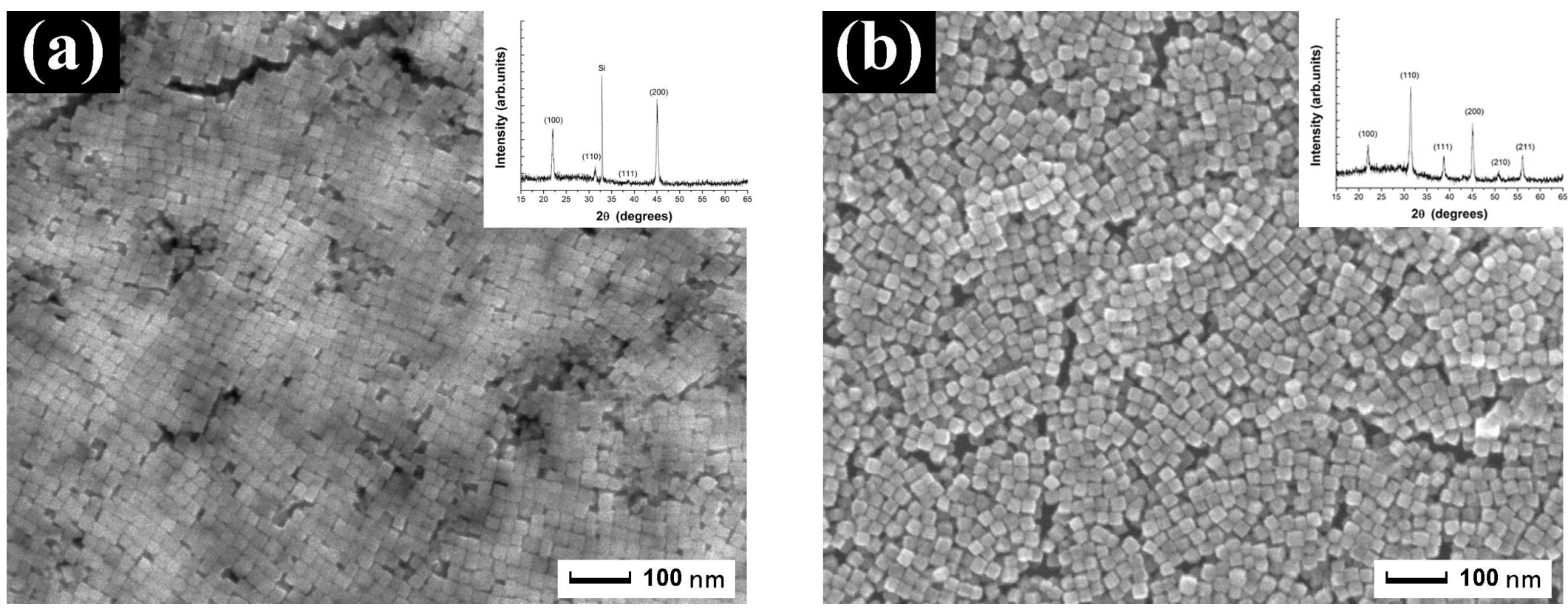
Figure 8
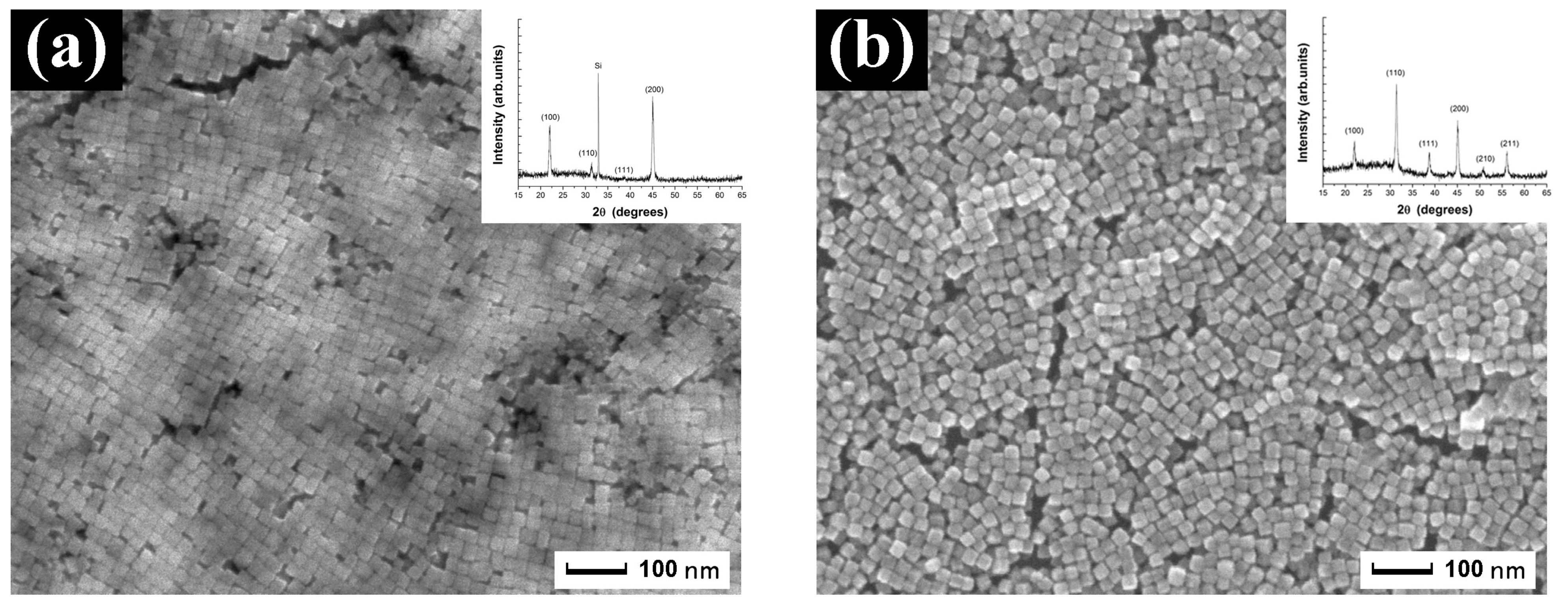
Graphical Abstract

Nanocrystal with terrace structure

Quasi-cube

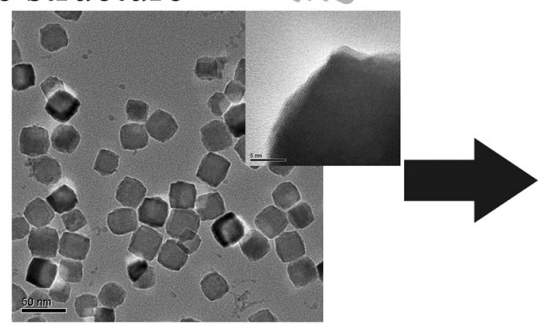

Nano-cube

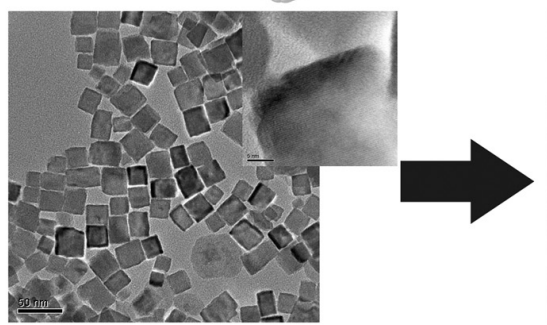

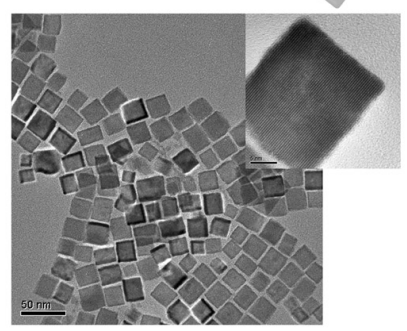

